\title{
Parts of the Whole: Logical Categories of Learning: Why Teaching QR is Hard
}

Dorothy Wallace

Dartmouth College, dorothy.wallace@dartmouth.edu

Follow this and additional works at: https://digitalcommons.usf.edu/numeracy

Part of the Higher Education Commons, and the Science and Mathematics Education Commons

\section{Recommended Citation}

Wallace, Dorothy. "Parts of the Whole: Logical Categories of Learning: Why Teaching QR is Hard." Numeracy 12, Iss. 2 (2019): Article 20. DOI: https://doi.org/10.5038/1936-4660.12.2.20 


\title{
Parts of the Whole: Logical Categories of Learning: Why Teaching QR is Hard
}

\author{
Abstract \\ This column introduces the reader to an essay by anthropologist Gregory Bateson on the nature of \\ learning. In that essay, he stratifies the learning process into categories based on what aspect of the \\ student's understanding is required to change in order to accomplish a given learning task. A discussion \\ of the first three categories is followed here by examples from quantitative reasoning tasks and a further \\ example from the ongoing discussion in the community of what numeracy entails. Bateson's \\ classification of learning into "logical categories" sheds light on what the goals of numeracy ask of both \\ student and teacher, as well as what may be needed beyond a single course to accomplish those goals.

\section{Keywords} \\ quantitative reasoning, numeracy, mathematics education, logical categories, Gregory Bateson \\ Creative Commons License \\ (c) (1) (9) \\ This work is licensed under a Creative Commons Attribution-Noncommercial 4.0 License

\section{Cover Page Footnote} \\ Dorothy Wallace, Contributing Editor of Numeracy, is a professor of mathematics at Dartmouth. She has \\ broad background in many kinds of mathematics, with numerous publications in pure, applied, and \\ educational topics. Her recent research papers in mathematical biology include some 30 undergraduates \\ among her coauthors. She was a charter board member of the National Numeracy Network and was a \\ founding co-editor of this journal.
}




\title{
Parts of the Whole
}

\author{
A Column by D. Wallace
}

The problem of how best to improve the numeracy of a society is a thorny one, addressing the learning process of a single student but rising in scale to include the management and alteration of an entire system of education. With the issue of quantitative literacy always in mind, this column will consider various aspects of the systemic workings of education: the forces acting on classrooms, teachers, and students and mechanisms of both stasis and change. With the issues of volume 9, the column has grown to include thoughts on pedagogy, in addition to continuing to explore strategies for systemic change in quantitative education.

\section{Logical Categories of Learning: Why Teaching QR is Hard}

In 1972 Gregory Bateson published a book of essays that he described as being essentially his entire life's work (Bateson 1972). Trained in anthropology but deeply interested in psychiatry, evolution and genetics, Bateson worked at a time when information was substantially scarcer than it is now. His highly cited book ${ }^{1}$ is the work of a deeply interdisciplinary thinker, forced to resort to the insights of evolution and the logic of mathematics as explanatory tools for understanding phenomena arising in psychiatry and anthropology.

It would be easy to dismiss his work as being out-of-date or too philosophical to be useful in the classroom (which was not his intent in any case). But one essay (Bateson 1972a) stands out as a comment on the challenges of learning, and therefore teaching.

\section{Bateson on Logical Categories of Learning}

Inspired by the logical categories of Whitehead and Russell's Principia Mathematica, (which argues on the basis of these categories that a set cannot be considered a member of itself, without leading to contradiction,) Bateson (1972a, 293) proposes the following categories of learning:

"Zero learning is characterized by specificity of response which- right or wrong- is not subject to correction.

Learning I is change in specificity of response by correction of errors of choice within a set of alternatives.

\footnotetext{
1 28,485 on Google Scholar (June 1, 2019).
} 
Learning II is change in the process of Learning $I$, e.g., a corrective change in the set of alternatives from which choice is made, or it is a change in how the sequence of experience is punctuated."

Bateson goes on to discuss Learning $I I I$ and $I V$, the construction of which can be inferred from the construction of prior categories. It is not easy to describe Learning II, much less III and IV, which occur rarely. Most of Bateson's examples come from behavioral psychology, from computer programming, and to a lesser extent from anthropology. At no point does he derive a pedagogical view point from his analysis, although others have since addressed this possibility. Nor does he pass judgement on the relative value of these types of learning, only asking whether a particular type of learning has adaptive value for "the organism" in some given context.

\section{Zero Learning}

Bateson (1972a, 284) succinctly describes zero learning as no change in the organism. He gives the example of the employee who learns from the factory whistle that it is 12 o'clock. At first take it appears that such learning is trivial, but Bateson points out that apparently complex behaviors can occur during zero learning. For example, a computer that has been programmed to play a board game may follow a series of heuristic rules that lead to complicated moves. No matter whether the computer wins or loses the game, it will follow exactly the same rules the next time it plays. Students who have once mastered an algorithm for solving a particular problem can do so over and over again. This is zero learning.

Many quantitative problems can be approached with a "guess and check" method. A student equipped with this approach and a calculator can answer endless questions while engaged in zero learning. Similarly, someone could learn that a particular statistical test gives a $p$-value for the difference in means of two populations. The student might use this test repeatedly in projects, whether its use is justified in the particular study or not. Unless inappropriate use occurs and is noted by the instructor, zero learning results from the repeated statistical exercise. Finally, a student may arrive the first day of a personal finance course perfectly able to compute the effects of compound interest on a loan, and may exit the course with this knowledge intact. Yet their personal behavior with respect to credit cards may indicate that zero learning has happened.

\section{Learning I}

Bateson (1972a, 288) gives rote learning as an example of Learning I. In rote learning, the behavior changes from being unable to answer a set of questions to being able to do so. Bateson emphasizes that Learning 1 is context dependent, with the context acting as a marker that elicits the learned behavior. 
Many QL examples fall into the Learning I category. The student can now compute a percent increase, or an expected value, or compound interest, whereas before the class they could not do so. Perhaps the student now has command of a body of facts or can correctly do unit conversions when asked. However, the context in which this learning has occurred may be restricted to the course in quantitative reasoning required by the institution.

The student may also have learned that course requirements in general have little to do with later courses, the student's major, or post-college plans. The learning that happened in the QR course may never be put to use when the course is over, because it is tied in the mind of the student to the particular context of the QR course.

There is another kind of Learning I, which is a form of unlearning due to lack of reinforcement. Outside the QR classroom, there may be no one demanding that students use the quantitative approaches and skill that they learned, and eventually these hard-won abilities disappear. Our colleagues may have learned not to expect or demand quantitative reasoning from their students.

\section{Learning II}

Bateson (1972a, 294) cites a study by Hull et al. (1940) showing that if one practices rote learning enough it is possible to get better at it. If rote learning is an example of Learning I, then improving one's ability represents a change in a type of Learning I and is thus an example of Learning II. Learning II has been given various names, perhaps the most descriptive being "learning to learn."

A student that is convinced of the value of asking quantitative questions, and with enough confidence to ask them in new contexts, is likely to increase his or her facility with quantitative tools and to seek to master new methods of inquiry for whatever task is at hand. This is the "habit of mind" mentioned in some definitions of numeracy, and an example of Learning II, "a corrective change in the set of alternatives from which choice is made." Numeracy as a habit of mind enlarges the set of possible responses to quantitative information. No longer forced to choose between "they are the experts so I guess they are right" versus "you can't trust anything in the news," the individual with a quantitative habit of mind can include responses such as "Do the numbers make sense to me?" and "I can read further technical information and judge for myself." This enlargement of the set of possible responses can be in regard to a specific set of contexts or problems, and may have to happen multiple times in order to address the wide variety of quantitative reasoning contexts.

Bateson observes that much of Learning II is unconscious and acquired early in life. Often the set of alternatives one is accustomed to using to solve problems works well enough that it is self-reinforcing, making any shift to a larger set of alternatives difficult for a person. As Bateson (1972a, 301) puts it, "The 
practitioner of magic does not unlearn his magical view of events when the magic does not work." He also points out that it lies somewhat beyond the stimulus/response cycle used to teach and measure Learning I tasks. Learning II, although powerful, is hard.

\section{The Goals of Numeracy}

The various definitions offered for numeracy include specific goals that cross multiple logical categories defined by Bateson. His description of these categories and how they work sheds some light on what may be needed to reach particular QR goals. It is clear that to achieve Learning I requires careful work by both student and instructor, and also reinforcement in subsequent contexts, whether they be later classes, internships, or other opportunities. Learning II includes developing the "habit of mind" we hope students will cultivate that inclines them to ask quantitative questions and test quantitative claims. It represents a shift in the framework the student uses to ask and answer questions, quite likely requiring systemic adjustment beyond the capacity of a single course to achieve. Learning II is difficult to arrange and difficult to measure, and is perhaps the most ambitious of numeracy's goals.

\section{References}

Bateson, Gregory. 1972. Steps to an Ecology of Mind: Collected Essays in Anthropology, Psychiatry, Evolution, and Epistemology. San Francisco: Chandler Publishing Company. Reprint available at http://ejcj.orfaleacenter.ucsb.edu/wp-content/uploads/2017/06/1972.Gregory-Bateson-Steps-to-an-Ecology-of-Mind.pdf (accessed June 30, 2019).

Bateson, Gregory.1972a. "The logical categories of learning and communication." In Steps to an Ecology of Mind: Collected Essays in Anthropology, Psychiatry, Evolution, and Epistemology by G. Bateson, 279-308. San Francisco: Chandler Publishing Company.

Whitehead, Alfred North, and Bertrand Russell. 1927. Principia Mathematica. 2. University Press.

Hull, Clark L., C. I. Hovland, R. T. Ross, M. Hall, D. T. Perkins, and F. B. Fitch. 1940. Mathematico-Deductive Theory of Rote Learning: A Study in Scientific Methodology. New Haven: Yale University Press. 